\title{
Coarctation of the aorta in a 6 month old
}

\author{
Brian T. Kloss • Joseph Morgan
}

Received: 6 October 2010 /Accepted: 20 October 2010 /Published online: 8 December 2010

(C) The Author(s) 2010. This article is published with open access at Springerlink.com

A 6-month-old male presented with increased respiratory efforts, a low grade fever, $\mathrm{O}_{2}$ saturations in the high $80 \mathrm{~s}$ and wheezing. Symptoms improved with nebulized albuterol. A chest X-ray revealed cardiomegaly and a right-

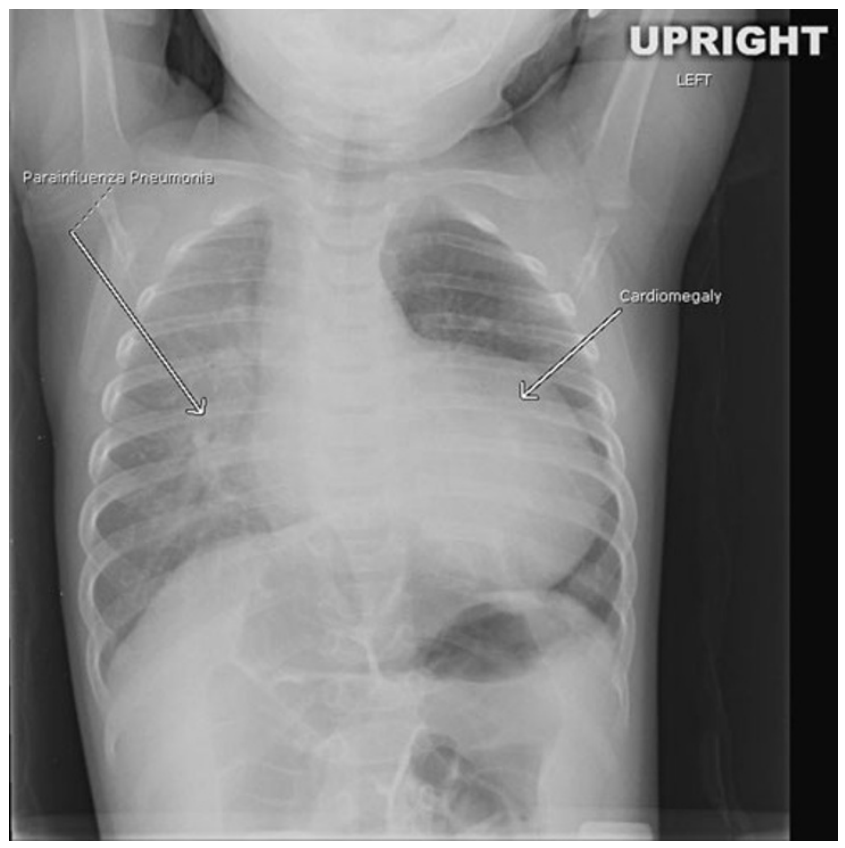

Fig. 1 Anteroposterior chest X-ray showing cardiomegaly and parainfluenza pneumonia

\section{B. T. Kloss $(\bowtie) \cdot J$. Morgan}

Department of Emergency Medicine, Upstate Medical University, 550 East Genesee Street,

Syracuse, NY 13202, USA

e-mail: klossb@upstate.edu

\section{J. Morgan}

e-mail: morganj@upstate.edu sided infiltrate (Figs. 1 and 2); EKG revealed criteria consistent with left ventricular hypertrophy (LVH). An echocardiogram confirmed coarctation of the aorta (Fig. 3).

Coarctation of the aorta is a narrowing of the lumen of the aortic arch classified as either "pre-ductal" or "post-ductal" based on the location relative to the origin of the left subclavian artery [1-3]. In $85 \%$ of cases, coarctation of the aorta is seen with other congenital defects [1]. Males are twice as likely to have coarctation of the aorta, although it is a common manifestation of Turner's syndrome [1,3].

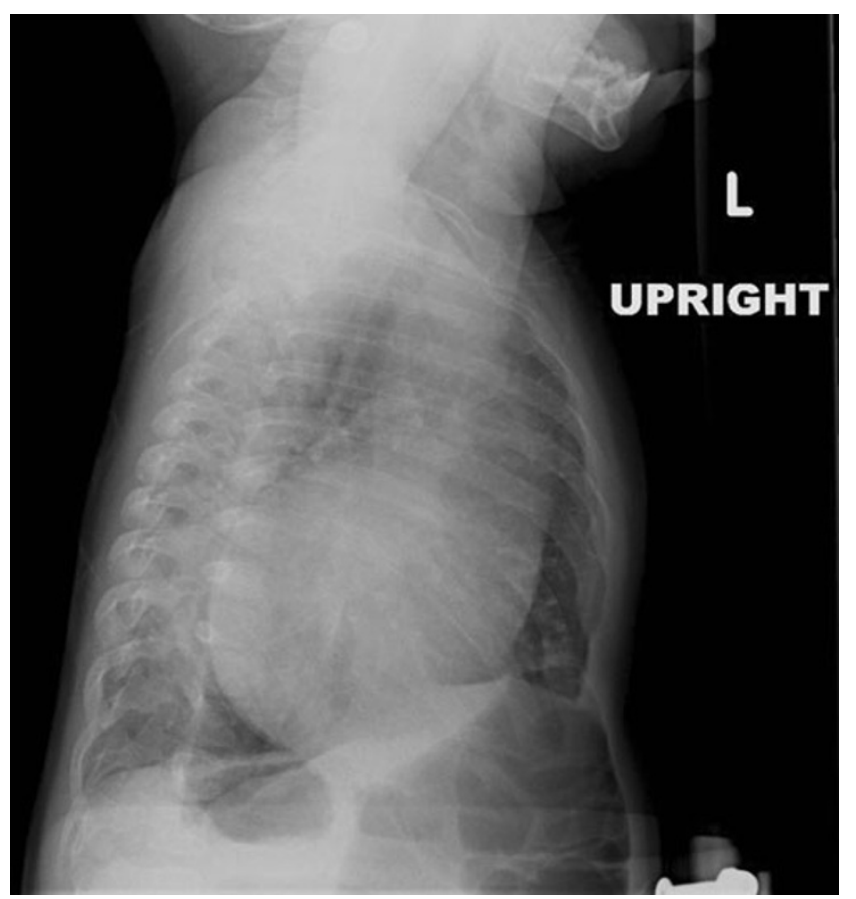

Fig. 2 Lateral chest X-ray showing cardiomegaly 
O8-MAY-2010 13:31:13

Vent rate

PR interval

QRS duratio

QT/QTc
P-R-T axes

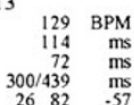

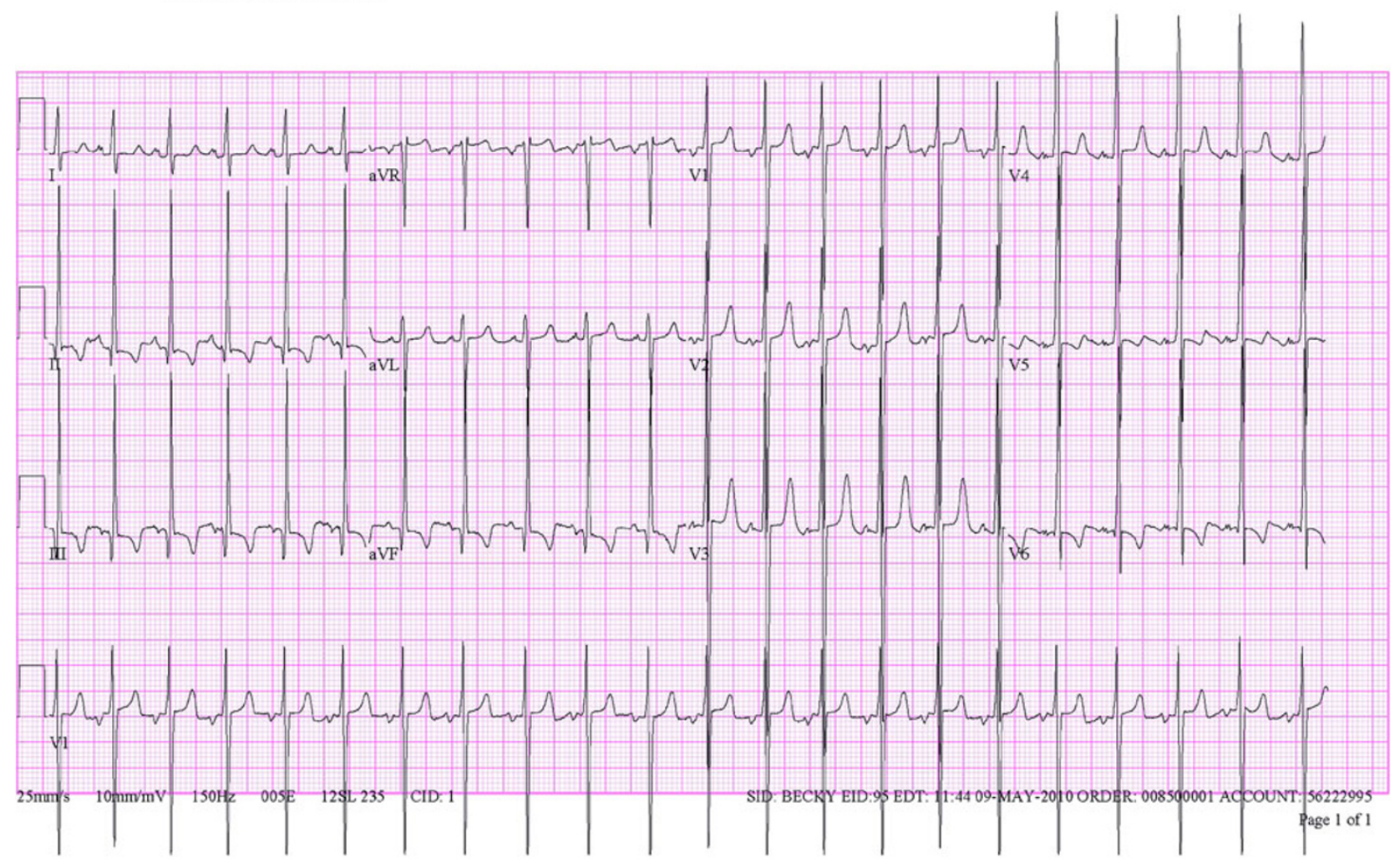

Fig. 3 EKG showing LVH consistent with cardiomegaly

The condition can also be sub-divided into infantile (within the first year of life) and non-infantile (delayed) presentation. When the ductus arteriosus closes shortly after birth, infants with coarctation can present with cardiovascular collapse and resulting cyanosis [1]. In the non-infantile presentation, collateralization of blood vessels (including intercostal, subclavian, vertebral, anterior spinal, and internal mammary arteries) allows for the distal aorta to be adequately perfused $[1,3]$. In the noninfantile presentation, upper extremity systolic hypertension, a short systolic murmur in the left interscalpular area, and diminished/absent femoral pulses can be seen in otherwise asymptomatic patients [1]. Older children and adults present symptomatically with dyspnea, headache, and/or leg fatigue $[1,3]$. Our patient presented early because a para-influenza pneumonia stressed his cardiopulmonary system, caused wheezing, and led a prudent physician to obtain a chest X-ray in this "first-time wheezer."
Acknowledgments Research was performed at the SUNY Upstate Medical Center Department of Emergency Medicine.

Conflict of interest None.

Open Access This article is distributed under the terms of the Creative Commons Attribution Noncommercial License which permits any noncommercial use, distribution, and reproduction in any medium, provided the original author(s) and source are credited.

\section{References}

1. Brickner E (2007) Congenetal heart defects. In: Textbook of cardiovascular medicine, 3rd edn. Lippincott Williams \& Wilkins, Philidelphia

2. Ferencz C, Rubin JD, Loffredo CA et al (1993) Epidemiology of congenital heart disease: the Baltimore-Washington Infant Study 1981-1989. In: Anderson RH (ed) Perspectives in pediatric cardiology, vol 4. Futura, Mount Kisco, NY, p 353

3. Crawford M (2009) Coarctation of the aorta. In: Current diagnosis and treatment cardiology, 3rd edn. McGraw-Hill, NY 